\title{
22. METEORS AND INTERPLANETARY DUST
}

\section{(METEORES ET LA POUSSIERE INTERPLANETAIRE)}

PRESIDENT: W. G. E1ford.

VICE-PRESIDENT: O. I. Bel'kovich.

ORGANIZING COMMITTEE: D.E. Brownlee, H. Fechtig, I. Halliday,

J.A.M. McDonne11, J. Rajchl, Z, Sekanina, A.N. Simonenko, K. Tomita

\section{INTRODUCTION}

Following past practice, a number of authors have contributed reviews of their own field. These contributions have been edited by the President to reduce major overlaps and in some cases, due to space constraints, to reduce the length of the reviews. When possible reference numbers in the Astronomy and Astrophysics Abstracts are used. As editor, the President accepts responsibility for any shortcomings in the report.

Attention is drawn to the Proceedings of a major symposium and several books published during the review period:

IAU Symposium 90, "Solid particles in the solar system" ed. I. Halliday and B.A. McIntosh, Reide1, Holland, 1980.

"Physics and Meteors:, V.A. Bronshten, Nauka, Moskva, 1981 (Russian), This book contains the present state of the art regarding the physical theory of meteors and fireballs and is recommended to anyone who is working in this area.

"Dust in the upper atmosphere and in space. The meteors", V.N. Lebedinets, 1981 , (Russian).

"Fireballs, Meteors and Meteorites" H.R. Provenmire, JSB Enterprises Inc., Florida, 1980.

"Solar system debris", R.A. Mackenzie, Dover, 1980. The last two books emphasize visual observations.

V. Guth.

It is with sorrow that we record the death of a noted meteor astronomer,

II. PHOTOGRAPHIC AND TV METEORS

Z. Ceplecha.

The Canadian MORP camera network continues in operation with 650 doublestation fireballs photographed by the end of 1980. Clear sky coverage has improved, with an annual average for at least two stations of $1.5 \times 10^{9} \mathrm{~km}^{2} \mathrm{~h}$ for the four years 1977-1980. Two probable meteorite falls were observed in January 1979 and September 1980, but no meteorites were located. About 100 fireball trajectories and orbits have been reduced in a flux survey which selects $30 \%$ of all MORP meteors observed under good conditions. A detailed study of the Innisfree meteorite fall is referred to in section $V$.

The European Fireball Network (EN) continues in routine operation with almost the same status as described in the last Report. Preliminary data on significant (low or bright) fireballs were published regularly in SEAN Bulletin (Smithsonian Institution, Washington). Final data on all fireballs photographed in 1977 were prepared for print (Ceplecha et al 1982). Three probable meteorite falls were photographed from several EN-stations in May 1979 (Zvolen, Slovakia; Ceplecha et al, 27.104.028), Oćtober 1979 (Harz, Germany) and January 1981 (Traunstein, Austria; Polnitzky, 1981; Ceplecha, 1981). The recovery efforts were not successful. Several groups of amateurs co-operated with the EN-project extending the covered area into the Netherlands and Belgium (Betlem, Roggemans). 
The Fireball Network in the USSR continued in regular operation. Babadzhanov and Getman (28.104.022) published data on 44 fireballs photographed in Dushanbe between 1957 and 1967. A new Firebal1 Network in India is expected to start operations in the winter of 1982 using a camera equipped with a fish-eye lens; the initial cover will be over $32,000 \mathrm{~km}^{2}$. Khotinok (28.104.005) pointed out the importance of observations of fireballs from stations orbiting a planet.

The classical smal1-camera projects have continued systematical work in the USSR (Kramer in Odessa; Benyuch in Kiev; Babadzhanov and Getman in Dushanbe) and in Japan (Tomita in Dodaira). Orbital data have been published by Benyuch et $\alpha$ (28.104.008, 060), Kramer and Markina (28.104.019) and by Drummond et $\alpha$ Z (27.104.006) of the NASA-NMSU Meteor Observatory. Additional efforts by amateurs were mostly limited to periods of several major meteor showers (Simmons and Povenmire in the USA; Betlem, Lier and Johannink in the Netherlands; Steayaert in Belgium; Rendtel in GDR; Wood in Australia; several groups in Japan; and others).

A reclassification of photographic fireballs by Wetheri11 and ReVelle (1981, IAU Colloq. 61) gave results essentially the same as found by Ceplecha and McCrosky (18.104.048), and there is no reasonable doubt that cometary fireballs are produced by bodies with quite different composition and structure from the bodies of meteoritic fireballs. Ceplecha (28.104.039) compared recent theories on the interaction of large-meteoroids with the atmosphere and proposed a new statistical criterion, AL, based solely on values directly accessible to photographic observations. The classification of fireballs by means of the new criterion is quite close to that by Ceplecha and McCrosky (18.104.048) based partially on photometric masses. The problem of the classification of fireballs was also attacked by Kramer et $\alpha 2$ (1980).

ReVelle (198la, 1981b) derived a new theoretical relationship for fireballs that allows for both deceleration and velocity dependent luminous efficiency; good agreement was found with data on three photographed and recovered meteorites. Pecina and Ceplecha (1982), using single body equations, computed the ablation coefficient at the point of maximum deceleration. The results are in good agreement with values derived from other methods. They also proposed a new more precise method for computing the meteor velocities from rotating shutter breaks that avoids the conventional interpolation formulae. Papers by Bronshten (27.104.038), Bronshten and Stanyukovich (26.104.024) and Padevet (28.104.014), also concerned with the modelling of fireballs are discussed in section $V$.

Masses and densities of meteoroids were determined by Benyuch (26.104.021), Kruchinenko and Kuznetzova (28.104.020). Lebedinets (1981) developed a theory of quasi-continuous fragmentation of meteoroids and was able to explain the SuperSchmidt meteor data by meteoroids of stony composition that need energy of $1.6 \times 10^{10} \mathrm{erg} / \mathrm{g}$ to fragment into particles of mass $10^{-5}$ to $10^{-4}$ grams.

The "instantaneous" (very short) exposure used for meteor cameras at several observatories in the USSR makes it possible to study more details of the time changes of the luminous volume around and behind the meteoroid. Kramer et al calculated photometric profiles of instantaneous meteor images both on the assumption of fragmentation of the parent body, and on that of the afterglow of evaporated meteor atoms $(1979,26.104 .016)$. Kramer et al (22.104.031) measured the relative velocities of meteor fragments using instantaneous meteor images. Babadzhanov and Getman (28.104.026) found that photometry of classical meteor images gives results 2 magnitudes brighter than photometry of the instantaneous image. This is in accordance with the results of Stoh1 and Hajdukova (25.104.010), who concluded that the photographic and visual photometric systems are mutually incompatible and prefer the explanation that the meteor photographic system is overestimated by -2 magnitudes. The results of Babadzhanov and Getman suggest 
that superposition of the wake radiation on the head radiation may be the cause. If this were true, the excess of photometric over dynamic mass might be at least partly attributed to such a phenomenon and several discrepancies in applying aerodynamic theories to meteor observations removed.

Benyukh (27.104.041) made photometric measurements of double-station meteors in different spectral regions. The luminous efficiency coefficients were derived from photographic meteors by Kramer and Shestaka (1977) and by Kruczinenko and Taranukha (26.104.017). Studies of light curves of eight orionid shower meteors in four spectral ranges and in integral light by Hajdukova and Hajduk (1981) have shown that radiation at the longer wavelengths increases with decreasing brightness of a meteor for every point on the meteor trail.

Inconsistencies in the data on the daylight fireba11 of 1972 , August 10 , were removed by Ceplecha (26.104.027), who obtained more data on velocities from the original authors. He also derived equations of motion of an ablating meteoroid in a near-horizontal trajectory and computed the no-atmosphere velocities before and after encounter with the Earth. The orbit was changed from Amor to Apollo type; the body may come close to the Earth again in 1997 with a relative time spacing of $4 \pm 8$ days.

The results of television observation of faint meteors have been published by Sarma and Jones (28.104.038), Galinskij et $\alpha$ l (27.104.042), Babadzhanov and Malyshev (27.104.007) and Tomita and Saito of the Tokyo Astronomical Observatory. The first double-station observations made using the TV technique were reported by Hawkes and Jones (28.104.027). The sensitivity limit was about $+7^{\mathrm{m}} 5$ and the maximum of the distribution of the 77 registered meteors was close to +4 ( 3 magnitudes fainter than the Super-Schmidt meteors). The observations show a smooth continuation of the velocity-height dependences of the Super-Schmidt meteors down to fainter magnitudes in contradiction to the backscatter radar measurements. The $A$ and $C$ levels of the beginning heights of the Super-Schmidt meteors are also present in the domain of faint TV meteors. A significant proportion of the 77 orbits is of the high-inclined long-period type. With recent improvements by Sarma and Jones the system characteristics are: limiting sensitivity $+9 m 5$, resolving power $3^{\prime}$, radiant error $\pm 30^{\prime}$, velocity error $\pm 0.3 \mathrm{~km} \mathrm{~s}^{-1}$, yield about 100 double-observed meteors per night.

\section{RADAR METEORS}

C.S.I. Keay.

Long-term radar studies of meteor streams continue to yield valuable results. Observations from Ottawa and Ondrejov have been combined by McIntosh and Simek (27.104.027) to show that the width of the Geminid shower at $61 \%$ of maximum varies from 62 hours for $+6^{\mathrm{m}}$ meteors to 31 hours for -1.3 meteors. The time of maximum flux varies with magnitude as $L_{0}=261^{\circ} .3-0.135 \mathrm{M}$. Particle variations around the orbit yield a period no more accurately than $1.6 \pm 0.1$ years. Jones and Morton (1981) find that the r.m.s. width of the Geminid radiant decreases from $1^{\circ} .3$ to $0^{\circ} .8$ over the shower duration. Hughes et al (1981) explore several mass segregation mechanisms to account for the $0^{\circ} .61$ difference between the ascending nodes of radio and visual meteoroids in the Quadrantid stream. Hajduk and Cevolani (1981) and Babadzhanov et al (25.104.046) report simultaneous investigations of streams from widely separated stations. Voloschuk and Kashcheyev (1981) have published a comprehensive monograph on the distribution of meteoroids in the Earth's neighbourhood and Tkachuk (1981) has found a geocentric velocity of $30 \mathrm{~km} \mathrm{~s}^{-1}$ for meteoroids with mass $\geqslant 10^{-6} \mathrm{~g}$. Baggaley (1980a) suggests that the presence of two components in height v. $10 \mathrm{~g} \cdot \alpha$ plots can be interpreted as evidence for two populations of meteoroids with different structures, a model also presented by Baggaley and Webb (27.104.025).

Znojil et $a Z(27.104 .026,1981)$ find that at $\lambda=8 \mathrm{~m}$ the relation between 
optical brightness $M$ and electron line density is $M=(40.8 \pm 0.4)-2.510 g \alpha$ down to a limiting optical magnitude of $7.9 \pm 0.6$.

Poulter (1980) suggests new experiments to resolve conflicting results for electron cooling times and the time dependence of the ambipolar diffusion coefficient. Hajduk et al (28.104.009) report further investigations of the sunrise effect in which persistent radar meteor echoes are shown to be enhanced by a factor of 1.5 declining to normal during the subsequent 8 to 12 hours. Cevolani and Hajduk (26.104.004) have found that the number of overdense meteor trains decreases to half or less in periods of maximum wind velocity.

Chumak et al (27.104.018) present an exact solution for radio-wave scattering which confirms the early work by Kaiser and Closs and shows that theix result, that the polarization radio is not larger than 2, applies to al1 types of meteor trails. A computer analysis by Ellyett and Kennewe11 (28.104.012) of Kaiser's meteor rate equation has shown that for typical sporadic meteor mass exponents of 2.35 the observed radar rates are quite sensitive to scale height changes.

An analysis by Hajduk and Prikryl (28.104.010) shows that range drifts are mainly due to motion of the reflection point along the trail towards the point of maximum ionization. Simek and Hajduk (1981) and Baggaley and Webb (1980) give evidence for non-specular reflection at angles up to $10^{\circ}$ and the latter report observations showing evidence of geomagnetic effects. Kalchenko (27.104.017) has shown that 2-day disturbances of meteor trail drifts are well correlated with changes in sign of the radial component of the interplanetary magnetic field. Periodicities in the drift rates of radar meteor trails in the equatorial zone are found by Kalchenko and Kashcheyev (1981) to correlate we11 with Wolf sun-spot numbers.

Absorption effects in the D-region have been investigated by Baggaley (1979a; 25.083.033) who has found that the ionization deposited by large meteors is inadequate by a factor of $10^{3}$ to account for LF radiowave absorption events and that geometrical factors, depolarizing effects and variations in meteroid mass index can produce effects in forward scatter radio-meteor data comparable with the sought-after absorption changes.

The tendency to avoid expensive systematic programs of meteor spectroscopy has continued during the three years since the last report. This is a natura1 consequence of the general lack of funding in meteoritics, and the large quantity of data that have not yet been fully analysed. Detailed analyses of a number of interesting spectra have been carried out, and interest in the theoretica1 explanation of meteor spectra has increased to the extent that roughly half of the published papers surveyed here are in the theoretical field.

The observational activity which has occurred frequently has included co-operating amateur astronomers running their own programs. Examples are Hans Betlem with the Dutch Meteor Society at Leiden, the Netherlands (S \& $T$ vol. 61 , pp. 66-67, 1981), and Ed. Majden in Courtenay, B.C., Canada. Among the professional astronomers Zdenek Ceplecha continues to organize programs of meteor spectrography at the Ondrejov observatory, Czechoslovakia, in connection with the Mid-European meteor-camera network (S \& T vo1. 61, pp. 300-301, 1981), John Russell has regularly observed the Perseid showers in August, and batteries of meteor spectrographs are exposed at the Springhill Meteor Observatory near Ottawa, Ontario, Canada, during the peaks of some of the major meteor showers. An active program of recording meteor spectra with television equipment continues at Ashkhabad, Turkman S.S.R., U.S.S.R. (21.104.039) but results from recent years 
have not yet been published. Instrumental advances in recording with electronic image-intensification on video tape have been described by clifton et al at the Marsha11 Space F1ight Center, Huntsville, Alabama, USA (26.031.545), and Mukhamednazarov et $a l$ at Ashkhabad, USSR (27.034.022).

A study of five sporadic meteor spectra, photographed at Dushanbe, USSR in the years 1958-1971, has been carried out by Saidov and Zolova (1980). A Perseid spectrum from 1975 has been analysed by Bouska and Mrkos (27.104.003). Using a special technique of "instantaneous photographs" Babadzhanov et a $Z$ have made a detailed investigation of a bright fireball photographed in 1975 (27.104.014, 28.104.026). Some 87 features were listed in this spectrum. Russell has correlated the strength of the $5577 \AA$ line of oxygen with meteor height, using Perseid spectra of $1977 / 78$ (28.104.029), and has suggested further correlations among other features in Perseid spectra (Russe11, 1980). A meteor with three bursts, photographed at Kiev University, USSR in 1968, has been studied by multicolor photometry by Benyukh (27.104.041). Smirnov and Kovshun at Odessa, USSR have discussed the differential photometry for $\mathrm{Na} \mathrm{I,} \mathrm{Fe} \mathrm{I} \mathrm{and} \mathrm{Ca} I I$, using three Czechoslovak spectra photographed 1960-62 (21.104.040). These same authors have suggested a method of analysis for calculating the relative number of atoms involved in various features of meteor spectra (Kovshun and Smirnov, 1978).

Park and Menees, following up work in 1976, have developed the theory of the production of NO and $N$ by an ablating meteoroid (22.104.008). Peak production of $\mathrm{N}$ is found to occur at a height of $95 \mathrm{~km}$, peak production of NO at $85 \mathrm{~km}$. Poole has explained various atomic and molecular species in meteor spectra by a two-step process - collisional excitation of atmospheric molecules, followed by resonant charge exchange with ablated meteoric atoms (25.104.001). Poole has also proposed the dissociative recombination of meteoric oxide ions in meteor trains as a source of the luminosity of faint trains and, apart from the D-lines of $\mathrm{Na}$, he finds that the main emitters are multiplets of $\mathrm{Fe}, \mathrm{Mg}$ and Ca (25.104.009). Kramer and Shestaka have found that the luminosity in the wakes of bright meteors is primarily due to the $\mathrm{H}$ and $\mathrm{K}$ 1ines of $\mathrm{Ca} \mathrm{II}$. They discuss various possibilities for the production of meteor wakes (27.104.020). Based on laboratory modelling Blokhin et al have calculated the effective excitation cross sections for several meteor atoms as a function of meteor speed in the atmosphere (26.104.029). Baggaley has continued to investigate the theoretical aspects of the luminosity of meteors and meteor trains. His papers (21.004.001, 22.104.013, $25.104 .039,25.104 .034$ and one with Cummack 25.104.033) are discussed in Section VIII.

A number of review papers have summarized the information available in the field of meteor spectroscopy. Gul'medov et al have listed some 2500 atomic 1 ines and molecular bands, identified in meteor spectra recorded in the period 1904-1970 (21.104.021). Baggaley has published two popular surveys of the theoretical work on meteor luminosity, the primary radiation (22.104.019) and the enduring emission (25.104.022). A more recent and detailed theoretical survey of the physics of the interaction between impacting meteoroids and the atmosphere was presented by Baggaley at the IAU Symposium 90 (28.104.023). In the same symposium Millman summarized the general progress in meteor spectroscopy over the last 115 years $(28.104 .028)$.

\section{PHYSICAL THEORY OF METEORS AND FIREBALLS}

D.0. ReVe1le.

In this section both recent advances in physical modelling and related observations of effects produced by meteors and fireba11s are considered.

Work related to meteor modelling has been carried out by Bronshten $(26.104 .023,26.104 .030,27.104 .021)$, by Sepri, Chen and 0'Keefe (1981), by Kalenichenko (27.104.039, 28.104.066), by Apshtejn, Pilyugin and Tirskij 
(26.104.025), by Rajch1 (25.104.012) and by Hunten, Turco and Toon (1980). The papers by Bronshten are an attempt to analyze the interaction between meteors and the atmosphere in the transition flow regime where the entry conditions are of neither the continuum or free molecular variety. The paper by Sepri et al although devised to study the behaviour of tektites in the atmosphere can be used to model meteors and fireballs which decelerate to velocities less than that of the earth's escape velocity. Unlike Bronshten, the latter authors have considered fragmentation phenomena and found a theoretical justification for the variable ablation observed in tektite strewn field samples. Kalenichenko attempted to model meteoric luminosity using a quasi-continuous fragmentation-ejection process, and in a separate paper considered the prediction of the meteor penetration depth into the atmosphere as a function of the minimum heat transfer coefficient. Apshtejn et al have developed a model of meteor flight allowing for a change in the shape parameter during entry. Values varying between 0.15 and 0.40 were found during direct computation in contrast to the constant classical value 0.33 . Rajch1 has begun an investigation of effects caused by non-equilibrium processes during meteor entry, with potential application to the rate of decay of $5577 \AA$ emissions. Hunten et al have used essentially the classical meteor theory in order to predict the eventual fate of evaporated meteor material and its possible effects on the atmosphere.

A relatively new area of meteor research concerns the effects of meteors on other planetary atmospheres. Dubin (1981) investigated the interaction between long period meteoroids (cosmoids) and the upper atmosphere of Venus and found significant differences between these interactions and those in the earth's atmosphere. Cook and Duxbury (1981) have reported on a fireball entry observed by spacecraft cameras in Jupiter's atmosphere. Similar observations made using infrared sensors in the earth's atmosphere have been tentatively analyzed by Rawcliffe (25.104.014). Work is continuing in this area at the stewart Observatory (D. Dearborn, personal communication, 1981).

With regard to the modelling of fireballs, major papers have appeared by Biberman et al (1980), by Passey and Melosh (27.082.092), by Halliday et al (1981) and by Bronshten and Stanyukovich (26.104.024). Related work has been carried out by Padevet (28.104.014), by Bronshten (27.104.038), by Ceplecha (26.104.027) and by Nevskii (1979). The paper by Biberman et al is a significant advance with regard to modelling ablation processes. Although precursor effects are not considered which could alter some of their conclusions especially for entry velocities greater than about $20 \mathrm{~km} \mathrm{~s}^{-1}$, ablation products absorption of shock wave radiation is included in the analysis. A self regulating or feedback effect is confirmed by direct numerical integration of the equations of radiation gas dynamics for flight conditions where heat transfer rates are greater than about $50 \mathrm{kw} \mathrm{m} \mathrm{m}^{-2} \mathrm{~s}^{-1}$. In other words at sufficiently large heat transfer rates the ablation products absorb shock wave radiation so efficiently that fluxes at the body itself are reduced relative to lower initial heat transfer rates.

Predictions made for a few initial Prairie Network meteoroid masses, using a combination of entry dynamics and stagnation point radiation transfer models, seem to confirm the photometric masses of Ceplecha and McCrosky (1976), but the precise reason for the agreement remains obscure.

Passey and Melosh considered break-up of fireballs and the resulting effects on crater field formation on the earth. A mechanical stagnation pressure model is considered along with effects produced by lifting forces, bow shock wave interactions between separate fragments and meteoroid rotation respectively. Halliday et al analyzed the Innisfree meteorite data and deduced curves for the luminous efficiency as a function of velocity and mass for the five separate trails for which both adequate flight data and ground related meteorite fragments were recovered. Further work needs to be carried out to relate cosmic ray track analyses of Innisfree and the flight data directly. The paper by Bronshten and 
Stanyukovich defends the classical meteor theory in direct response to the proposed ablation mechanism of Petrov and Stulov (1975).

In related work, Padavet applied his dynamic coma model to the Prarie Network fireballs and proposed that a non-classical reverse rocket model be developed in order to explain the anomalous behaviour of some of the fireballs. Bronshten investigated the deduction of ablation parameters directly from fireball data as was accomplished by Ceplecha (1967) using a different approach. Also, Ceplecha has used the correct orbital data of the daylight fireball of August 10, 1972 in order to infer aerodynamic and initial mass estimates. Nevskii (1979) investigated the possible build up of positive electric charge on meteorites travelling at hypersonic speeds. Electrical discharge phenomena not considered by others may have bearing on a more complete explanation of the observed effects of the Great Siberian Meteor of 1908.

Regarding acoustic, infrasonic and anomalous (electrophonic) sounds from fireballs, work has continued despite the negative results from the infra-sound station in the Canadian MORP network (McIntosh, personal communication, 1981). Bedard and Greene (1981) determined the altitude and bearing of a firebal1 event over Colorado in 1975. Keay $(27.104 .022 ; 28.104 .044 ; 28.104 .056)$ analysed reports of anomalous sounds from the 1978 New South Wales fireball and proposed a source mechanism involving the interaction between the geomagnetic field and the turbulent plasma region generated in the wake of large fireballs/meteorites. Recently (Acoust. Soc. Am., Los Angeles, Nov. 1980), ReVelle and Wetherill suggested the use of the AFTAC fireball infrasound data set in future modelling efforts of low frequency sound propagation. At the Int. Symp. Acoustic Remote Sensing, Calgary, June 1981, ReVelle and Delinger reported a connection between Lamb edge mode predictions of meteoroid energies and predictions made using the wave period at maximum amplitude, as in the influx calculations of ReVelle (28.104.040). At the same symposium, Kraemer and Bartman discussed the estimate of mass of Prairie Network firebal1 No. 42556 (Ceplecha and McCrosky - Group II) from the infrasound data and the known entry velocity. Preliminary values agree with the photometric mass of Ceplecha and McCrosky (1976), but with a large uncertainty due to aerodynamic factors.

\section{METEOR ORBITS}

Z. Ceplecha.

While data on accurate orbits still come from double- and multi-station photographic projects as mentioned in Section II, the greatest progress in acquiring accurate orbits of optical meteors was achieved in the double-station data on TV meteors, extending our knowledge to objects three magnitudes fainter (Hawkes and Jones, 28.104.027) than those accessible to photographic techniques.

Orbits of photographic fireballs from several networks were regularly computed and published, as were some orbital data on small camera meteors (see Section II). Halliday and Griffin (1981) have studied the variation in the rates of meteorite falls as a function of time of day, season and geographic latitude, using firebal1 data from the Prairie Network, European and MORP camera networks, which are believed to be associated with chondritic material. The study obviates the assumptions regarding social effects which are required in the treatment of statistics of recovered falls. Galibina and Terenteva (28.104.033) chose 15 orbits of the Prairie Network fireballs and computed them $10^{5}$ years back in time with perturbations of 4 outer planets.

The increasing use of large computers to model orbital evolutions particularly of meteor streams, was evident from the number of published papers. The evolution of the orbit of the Quadrantids over long and short terms was studied in a series of papers by Williams et $a z$ (26.104.008), Murray et $a z$ (27.104.001), Hughes et al (26.104.009, 28.104.035 and 1981). During a broad interval, 1100 - 
1800 years before the present, the Quadrantids orbit had a much smaller perihelion distance and a lower inclination. This is in accord with Cook's classification of the beginning heights of Quadrantids as B level group $(4.104 .034,035)$. The orbital evolution of the Quadrantids was also studied by Babadzhanov and Obrubov who took into consideration non-gravitational effects and perturbations of 6 planets $(28.104 .036)$. The same paper also presented computations of the changes of the Geminid orbit as well as another paper of the same authors (27.104.046), and also papers by Galibina and Terenteva (26.104.034), and Obrubov and Sherbaum $(25.104 .057)$.

Kondrateva and Reznikov (25.104.013) using model computations concluded that the meteors of the Pons-Winecke comet observed in 1916 were ejected from the comet during the period between 1875 and 1880 . The evolution of the orbit of Halley's Comet and its meteor streams, Orionids and n-Aquarids, was studied by Babadzhanov and Obrubov (27.103.704). The orbital evolution of different types of meteor showers with perturbations from Jupiter and Saturn was investigated by Sherbaum (26.104.020, 25.104.004), Sherbaum and Kazantzev (1980), and Kruchinenko and Sherbaum (28.104.070). The motion of meteoroids close to a $1: 3$ ratio with Jupiter allows for resonance changes of the semi-major axes to $2.5 \mathrm{a} . \mathrm{u}$. (Simonenko et al, 1980, Kazantzev and Sherbaum, 1981).

The probability of meteoroid collisions with the Earth and the distributions and orbital life-times of meteor streams were investigated by Kramer et al $(25.104 .043,26.104 .015,28.104 .041)$. The influence of secular perturbations on the structure of meteor showers, in particular the Geminids and Taurids, was studied by Kramer et al (21.104.038) and Kramer and Timczenko (1981). The differences between the orbital life-time of a meteor stream and the period of visibility of the corresponding meteor shower were pointed out by Kramer and Shestaka (1981).

In the past, a number of authors have claimed an association of several minor meteor showers with the Comet Lexell. Kresakova examined such a relationship in a thorough study (28.104.013) using photographic, radar and visual data. Among 4000 photographic meteor orbits not a single object can be unambiguously related to Comet Lexe11 and the contribution of this comet to the total annual meteor influx is less than 0.05 percent.

Wheaton and Jones (University of Western Ontario) developed a computer program for integrating the equation of motion including the Poynting-Robertson effect. They studied the orbital evolution of Geminids and found that there is too much scatter in the available radio meteor data to calculate reliable stream ages and that planetary perturbations are insufficient to account for the present deviation of the stream. Jones re-analysed the 20 year radar Geminid observations of McIntosh and Simek; if their data consisted of essentially "pure" Geminids then the stream must have significant fine structure, which could survive a reasonable length of time only if the surface of the meteoroids have a substantial thermally insulating layer. Several models for radiant and orbital distributions and for hourly rates of sporadic meteors were proposed (Stoh1 28.104.032, Antropova et al 25.104.029, Tkachuk 25.104.016).

The observations of individual orbits of faint meteors is still the domain of the radar technique. A catalogue of 5317 individual orbits of radar meteors down to +12 magnitude was published by Kashcheev and Tkachuk (28.002.034). The same authors presented distributions of orbital elements whose annual variation proved to be larger than changes between the corresponding months of different years (26.104.013, 27.104.013). The average dimensions and eccentricities of the orbits decrease with decreasing meteoroid masses. The effects of observational selection on orbital elements have been studied by Tkachuk $(26.104 .014,1981)$ and Tkachuk and Matzenko (1981), and the problems of the distinction threshold 
examined by Voloshuk et al (1981a, b). The distribution of orbit inclinations was investigated by Andreev et al (27.104.009), while Tkachuk (1978) determined the distributions of apparent, geocentric and heliocentric radiants. The density of heliocentric radiants proves to have minima at solar and antisolar points, but not at the Earth's apex. A mathematical model of radiant distributions for each month was presented by Voloshuk and Kashcheev (1981).

The radiation pressure and the Poynting-Robertson effect were applied in analytic and numerical studies of the orbital evolution of dust particles. Burns and Soter (28.063.041) presented a straightforward derivation of the radiation forces in terms of classical physics and they were able to remove Robertson's restriction to perfectly absorbing particles. Lyttleton (28.104.004) studied the motion of dust relative to the parent comet. Kerket (1981) derived expression for the radiation force including the effect of asymmetry of the therma1 reradiation and of inelastic scattering (fluorescence). Dmitrievskij (1980) solved a problem of dust particle motion in a radiation field including the increase of the particle radius due to heating and found that the argument of perihelion changes systematicly. The change in the orbits of dust particle induced by increasing solar luminosity was investigated by Simonenko and Levin (28.106.034). Schuerman (28.042.031) generalized the solution of the classical three-body problem including the radiation pressure and $P R$ effect. The orbits of dust particles close to the Sun have been solved numerically by Schwehm (28.106.042) taking into consideration radiation forces and heating effects. For further discussions of the orbits of interplanetary dust see Sections $X$ and XI.

VI

METEOR SHOWERS

B.A. Lindblad.

Theoretical studies of meteor stream formation have been published by Hughes (21.104.007), Katasev and Kulikova (28.104.069) and Babadzhanov et al (1980). The influence of planetary perturbations on meteor streams has been treated in a series of papers by Sherbaum (21.104.015, 25.104.004, 26.104.018, 26.104.020, 28.104.070). The influence of Poynting-Robertson and other drag effects on the major meteor streams has been studied by Babadzhanov and Zausaev (1980). See also papers by Lyttleton (28.104.004), Evdokimov (21.104.032) and Galibina and Polyakhova (22.104.050).

The relation between comets and specific meteor streams has been discussed in several papers. Meteors associated with comet Grigg-Skjellerup (1976b) are discussed in (22.103.752). The origin and age of the Pons-Winnecke meteor shower is analysed by Kondrateva and Reznikov (25.104.013). The D-criterion for identifying associated orbits has been discussed by Kramer (28.102.052), Kramer et $a Z$ (1980) and Drummond (27.104.048, 1981). Statistical problems in detecting meteor streams and meteor associations have been discussed by Andrev and Lezarev (21.104.023). See also Vorontsov-Velyaminov (28.104.064).

Amateur recordings of meteors continue at a high level of activity in Great Britain, Belgium, Holland, Germany, Czechoslovakia, Japan, Australia, USA and other countries. The observations are reported in British Astron. Assoc. Cir., in Radiant (Dutch Meteor Society), in Meteor Reports of the Slovak Astron. Soc., in Nippon Meteor Astron. Circ., in Meteor News and in various other newsletters. Radiant lists and catalogues based on visual, photographic and radar studies have been compiled by Becher (1980), Mackenzie (1981) and Mims (27.104.032). Southern meteor radiants have been reported on by Morgan (26.104.010) and Bennett (1978). The very comprehensive catalogue by Mackenzie includes data from both hemispheres. Since few professional groups maintain continuous meteor patrol the contribution of amateur meteor observers is of great importance, in particular for the detection of new meteor showers. A critical comment is, however, appropriate: there is in the various radiant catalogues little or no discussion of the statistical significance of the listed radiants. The problem of spurious radiants 
has recently been discussed by McLeod (1981).

Visual and telescopic meteor observations are regularly carried out in Czechoslovakia (Novakova 1979, 1980); see also Meteor Reports of the Slovak Astr. Soc. Numerous meteor observers in Europe are organized in the Federation of European Meteor Astronomers (FEMA), and several USA groups in the International Meteor Research Network. As before the American Meteor Society collects reports on meteor observations from many countries.

Radar observations of the Quadrantid shower have been reported by Andrev et al (25.104.054). Visual observations in 1979 are analyzed in (26.104.003). Lockanadham (28.104.037) summarized visual observations in 1961-76 and compares the visual and radar activity of the Quadrantid shower. The orbital evolution of the Quadrantid stream is analyzed in a series of papers by Hughes et al (26.104.008, 27.104.001, 28.104.035). Encounter conditions with the Earth are discussed by Babadzhanov and Obrubov (27.104.049, 28.104.036). A search for possible parent comets for the Quadrantid meteor stream has been made by Kondrateva $(28.104 .068)$.

Hajduk (28.104.034) has analyzed Springhill radar data 1958-1967 to determine the structure of the Eta Aquarid stream. Eta Aquarid observations in 1978 have been described by Clark (22.104.040). The associations of Comet Halley with the Eta Aquarid and Orionid streams is discussed in (27.103.704) and by Babadzhanov et al (1980). Hindley and Taylor (22.104.017) have compiled data on the AlphaCapricornid meteor shower, based mainly on A.V. Nielsens fireball catalogue. Television observations of the Delta Aquarid meteor shower are reported by Sarma and Jones $(28.104 .038)$.

The Perseid meteor stream has been discussed by Nasyrova and Nasyrov (21.104.016), Andrev et al (22.104.030) and Korpikiewicz (22.004.039). The radiant area of the Perseid shower has been studied by Jones and Sarma (26.104.002) using TV techniques. Radar-visual observations of the Perseid shower have been carried out in Sweden every year since 1953. In view of the expected return of the parent comet (1862 III) observations of the Perseid shower during the next years are very important. A discussion of the orbit of the parent comet and observations 1 prospects has been published by Kleine and Kasten (27.103.601).

The relation between the Draconids and comet Giacobini-Zinner is discussed by Babadzhanov et al (1980). Radar observations in 1974-75 of the Orionid stream are reported by Hajduk and Simek (25.104.036) and Babadzhanov et al (25.104.046). For a discussion of the association with Halley's comet see Babadzhanov et al (1980) and (27.103.704). The luminosity functions of the 1969 Perseid and Orionid showers have been analyzed by Krisciunas (28.104.058). Exceptionally low values of the mass exponent are reported.

Visual observations of Geminid meteors have been described by Rao Srirama et al (21.104.045) and Lokanadham (28.104.037). Observations at the Skalnate Pleso Observatory in 1944-74 are discussed by Porubcan et al (28.104.011). Observations in Australia are described in (21.104.046). The period of the Geminid stream has been studied by Jones (21.104.012), Porubcan (22.104.002) and McIntosh and Simek (27.104.027). The last paper discusses stream structure based on 20 years of radar data. The activity of the Geminid shower in 1974-76 is described in (22.104.023) and in Porubcan and Stoh1 (25.104.011). Obrubov (28.104.061) presented a theoretical study of the Geminid stream. 
During the review period there had been significant work on the life histories of meteor ablation products before their eventual wash-out in the troposphere.

The close association between meteor influx and the $90 \mathrm{~km} \mathrm{Na}$ layer found in the lidar studies of Megie and Blamont (1977) is confirmed by the rocket massspectrometer findings of Hermann et al (1978) showing the build up of metal (M) ions after shower activity. Lidar observations (Megie et al 21.082.020; Richter et al 1981) delineated the height profile of $\mathrm{Na}$ atoms. Conversion of ablated $\mathrm{Na}$ atoms to $\mathrm{Na}^{+}$via $\mathrm{O}_{2}^{+}$and $\mathrm{NO}^{+}$charge transfer and photoionization occurs during daytime. Transport of $\mathrm{Na}^{+}$and $\mathrm{M}^{+}$ions by wind shear, and the cluster chemistry of $\mathrm{Na}$ and $\mathrm{Na}^{+}$, particularly sink processes involving high order water clusters, have been considered by Richter and Sechrist (1979, 25.082.079) and Richter et al (1981). Aerosols or dust may provide reaction centres for ionic reactions and loss of $\mathrm{Na}$ at the bottom side.

Hunten et al (1980) consider that particles formed from the condensation of meteor ablation products can serve as condensation nuclei in the stratosphere and so act as a sink for metallic atoms and ions. From a study of meteoric vapour and dust in the stratosphere Turco et al (1981) conclude that, except at low heights where sulphate aerosols would dominate, stratospheric aerosols are predominantly of meteoric origin.

The problem of the transport of metal ions down to the stratosphere in gas phase form has been considered by Liu and Reid (1979) who also gave a model of the expected behaviour of $\mathrm{NaOH}$. Murad and Swider (1979) concluded that $\mathrm{NaOH}$ and other metal hydroxides will react with both hydrated protons and chlorine containing species such as fluorocarbons. The existence of $\mathrm{Na}$ in gas phase form or as aerosols below the mesopause was addressed by Ferguson et al (1981) who (from laboratory evidence) pointed out that $\mathrm{MgOH}^{+}$(or its hydrated form) can be lost in the presence of stratospheric $\mathrm{HNO}_{3}$. Perry (1980) concluded that ion reactions would convert any gaseous forms of sodium to $\mathrm{H}^{+} \mathrm{NaOH}$ clusters. Aikin (1980) calculated the ion pair production at $30-60 \mathrm{~km}$ due to photoionization of $\mathrm{NaOH}$ and $\mathrm{CaOH}$ and suggested that studies of ion density variations in the upper stratosphere should provide evidence of meteoric compounds. The high resolution observations of Arijs et $\alpha Z$ (1980) suggested that neither $\mathrm{NaOH}^{+}$nor $\mathrm{MgOH}^{+}$is dominant at night-time in the stratosphere.

The optical study of Gadsden (1978) and the work of Arnold (1980) on gas to particle conversion in super-saturated conditions suggest that aerosols and noctilucent clouds at the mesopause need no meteoric source, water vapour being responsible.

The dependence of the ambipolar diffusion coefficient $D_{a}$ of a meteoric plasma on the geomagnetic field has been studied experimentally by Baggaley and Webb (1980) who found a clear magnetic field inhibition of diffusion for heights $>100 \mathrm{~km}$. Webb (1981) emphasized that while below $95 \mathrm{~km}$ diffusion is determined by $2 \mathrm{D}_{+}$, above this height the diffusion coefficient depends on train orientation to the magnetic field, electron line density and the background ionization density. The findings are in accord with theoretical work. Diffusion of a meteoric plasma containing two species of positive ion was considered by Novikov et al (1981) while the details of coulomb collisions in a train are given by Levitsky (1978).

Ionization loss in meteor trains was described by Bibarsov et al (28.104.059) and Baggaley (22.104.013) related train metal ion chemistry to the limitation in duration of very long meteor radar echoes and also considered (Baggaley 1979a) the effect of very intense meteoric ionization on LF propagation. Sporadic meteor 
echo durations observed by McIntosh and Hajduka (1977) were in accord with simple metal reactions governed by $\mathrm{O}_{3}$ and 0 , and the diurnal variations are explained well by the model given by Baggaley (25.104.034) for the dependence of observed overdense meteor echo duration distributions on mean meteor velocity. The recombination of ionization in underdense plasma was shown to be negligible (Baggaley 25.104.039).

Concern for the validity of estimates of scale height and $\mathrm{D}_{\mathrm{a}}$ from echo studies (Forti, 21.082.027) was shown to be unfounded by Baggaley (1979b). Mu1tifrequency observations of echo decay rates and a bistatic experiment were undertaken to delineate train irregularity scales and wind shear (Baggaley 28.104.015). The influence of non-uniform winds on measurements of $D_{\text {a }}$ was discussed by Novotny $(21.104 .020)$ and the statistical analysis of scatter diagrams of $D_{a}$ versus height was discussed by Baggaley (28.104.023). Hawkes and Jones (22.104.025) modelled initial radii $\left(r_{i}\right)$ from a consideration of meteoroid rotation. Two wavelength studies of Baggaley $(28.104 .016)$ found a linear relationship between $r_{i}$ and meteor velocity, with $r_{i} \propto \rho^{-a}$ where $\rho$ is the atmospheric density, and $\mathrm{r}(100 \mathrm{~km})=1.5 \mathrm{~m}, \mathrm{a}=0.42$. In a triple wavelength study of meteors with density $\gtrsim 10^{15} \mathrm{~m}^{-1} \quad$ Baggaley and Fisher $(28.104 .002)$ found $\mathrm{r}(100 \mathrm{~km})=5.0 \mathrm{~m}, \mathrm{a}=$ 0.63 . Using underdense echoes Baggaley (1981a) determined $\mathrm{r}(115 \mathrm{~km})=1.8 \mathrm{~m}$, suggesting that $a=0.26$.

From comparisons between sodium nightglow, lidar data and the magnitude of enduring visual meteor trains, Baggaley (21.104.001) suggested that the sodium catalytic mechanism is responsible for persistent train luminosity. Baggaley and Cummack (25.104.033) considered the mechanisms limiting the life of emitting species in a train and showed that ' $\mathrm{O}_{3}$ depletion, molecular and turbulent diffusion and surface brightness reduction would limit the duration of visual trains to less than one hour for a large fireball meteor; the figures accord well with the known statistics of the occurrence of trains. For trains enduring for some minutes the formation of metal oxide ions and subsequent dissociative recombination to produce excited metal atoms was proposed by Poole (1978) though Baggaley (1978) pointed out that the crude available data on spectral distribution of train light argues against such a mechanism. Hapgood (28.104.007) obtained an estimate of the photon emission in the near infra-red of a long enduring meteor train. He and Baggaley (1981b) put forward alternative mechanisms for the emission. There is strong evidence that the $5577 \AA$ emission from atomic oxygen recorded in meteor wake spectra is a result of charge transfer followed by dissociative recombination (Baggaley 21.104.003, 28.104.023).

The cause of the inverse correlation between meteor rates (visual and radar) and sunspot numbers variations continues to be sought. Lindblad (21.104.027) found that a $20 \%$ decrease in meteor rates occurred about 3 days after the passage of a solar wind sector boundary. Ellyett and Kennewell (28.104.012) have shown that for mass distribution indices $s>2.0$ a decrease in scale height $H$ would yield an increase in observed rate; for $s=2.5$ a $30 \%$ decrease in $H$ would be expected to produce an increase of $24 \%$ in radar rate. Elford (28.104.024) showed that differences between summer and winter standard atmospheres can produce the observed changes in rates.

IX TEKTITES $\quad$ B.P. Glass.

The last few years have witnessed a renewed interest in tektite research. There appears to be at least three reasons for this: (1) application of techniques developed in the study of lunar samples to terrestrial problems; the discovery of tektite-like glasses associated with an impact crater (Zhamanshin) in the USSR; and (3) the possibility that large impacts (including tektite events) may have triggered climatic changes and extinctions. 
Some authors maintain that Libyan Desert glass is a kind of tektite; however, e.m.r. spectroscopy indicates that, unlike tektites, Libyan Desert glass was fused under oxidizing conditions (Weeks et al 1980). Tektites (probably Australasian) were reported from Northern Thailand (Yabuki et al 1981), but papuanites (translucent green glasses found in New Guinea) were shown to be of probable artificial origin (Visker et al 28.105.084). Microtektites in deep-sea sediments cored outside the known limits of tektite strewnfields have been used to extend the boundaries of the Australasian, Ivory Coast and North American tektite strewnfields (Glass et al 28.105.150). The North American strewnfield, for example, appears to extend at least halfway around the Earth and contains at least $10^{11} \mathrm{~kg}$ of tektite glass.

Mason (1979) found that australites have a more restricted range in composition than microtektites from deep-sea sediments south and west of Australia and argued against claims for a common origin for australites and microtektites. This position is supported by the suggestion that australites fell only $7000-20,000$ years ago (Chalmers et al 1979). Arguments supporting a time of fall of 700,000 years for the australites and common origin for australites and Indian Ocean microtektites are given by Glass (1979). Recent findings concerning Darwin glass in Tasmania also support a time of fall of 700,000 yrs. (Fudali and Ford, 26.105.060).

The argument over the origin of tektites continues. Although some investigators support a lunar volcanic origin (see for example, 0'Keefe 28.105.083), most investigators support a terrestrial impact origin. (One author, Crawford, 1979, supports a terrestrial volcanic origin). Calculations indicate that the observed variation in amount of ablation observed on tektites could have been produced at velocities greater than the Earth's escape velocity, if the tektites entered the atmosphere in a swarm (Sepri et al 1981). This result is consistent with an extraterrestrial origin for tektites; however, major element composition (Bentor 1979), nitrogen concentrations (Shukla et $a l$ 1979), and lithium concentrations (Shukla and Goel, 1979) of various tektites all support a terrestrial impact origin. Sm-Nd and $\mathrm{Rb}-\mathrm{Sr}$ isotopic studies of Australasian tektites (Shaw and Wasserburg 1981), lithium concentrations of various tektites (Shukla and Goel, 1979), and mineral inclusions found in Muong Nong-type tektites from Indochina (Glass and Barlow, 25.105.231) and in Czechoslovakian tektites (moldavites) (Jung and Weiskirchner, 27.022.047) all support a terrestrial sedimentary deposit as the parent material.

If tektites were formed by terrestrial impact events, then there should be a crater associated with each strewnfield. The Ries crater in Germany and the Bosumtwi crater in Ghana have been suggested as the source of the moldavites and Ivory Coast tektites, respectively. Trace element studies of the tektites and crater material support this suggestion (Haskin et $a Z, 1980$ ). The impact breccia at the Bosumtwi crater was found to have a normal polarity and this data along with radiometric age data, indicates that the crater was formed during the Jaramillo geomagnetic event (Jones et al 1981). This agrees with the observation that the Ivory Coast microtektites are found near the base of the Jaramillo event in cores from the Atlantic Ocean (Glass et al 28.105.150). Candidate source craters for the Australasian tektites include a buried crater in Antarctica, an unverified and undated crater in Cambodia (25.081.036), Elgygytgyn crater (Siberia) and Zhamanshin crater (USSR). There is no evidence for the Antarctic crater (Bentley, 26.105.030) and Elgygytgyn crater is too old (Storzer and Wagner, 27.105.158). Irghizites from the Zhamanshin crater are compositionally very similar to some Australasian tektites (Glass, 1979; Taylor and McLennan, 26.105.016; Van Patter et $a$ 2 1981) and the crater and tektites appear to have the same age (Bouska et al 1981), but the crater may be too small to be a viable source for the Australasian strewnfield (Taylor and McLennan; Bouska et al; Baldwin 1981). A further complication is the suggestion by Storzer and Wagner 
(1980) that the australites are older than other Australasian tektites, indicating that at least two separate events were involved in the formation of the Australasian strewnfield. Possible crater sources for the North American tektites are, Popigai (northern Siberia), Lake Winapitei and Lake Mistanstin (Canada) (Bottomley et al 1979), and an undated crater in South Texas (King, 1979). Storzer and Wagner (27.105.158) suggest that Popigai crater is too young.

There is some evidence to suggest that at least three of the four known tektite events were associated with reversals of the Earth's magnetic field (see Glass et al 28.105.150). There is also some data suggesting that extinctions of marine organisms were approximately synchronous with some of the tektite events (Glass et $a l$ 28.105.150). It is speculated that the extinctions may have been caused by climate changes triggered by the tektite events ( $0^{\prime}$ Keefe, 1980).

\section{$\mathrm{X}$ INTERPLANETARY DUST DISTRIBUTION AND DYNAMICS}

H. Fechtig.

The main progress in this field originates from three different sources: project Helios, project Pioneer 10/11, and lunar microcraters.

Two dust sensors on each of the Helios spacecrafts have scanned between 1 and 0.3 A.U.. One sensor (ecliptic sensor) scans in the ecliptic plane, the other (south sensor) is tilted towards the ecliptic south pole and scans off the ecliptic plane. The two sensors are sensitive to particles in the mass range between $10^{-17}$ and $10^{-8} \mathrm{~g}$. The time of flight mass spectrometer has only a limited mass resolution of $\mathrm{m} / \Delta \mathrm{m} \approx 5$. Both sensors are identical, except that the ecliptic sensor is covered by a $0.4 \mu \mathrm{m}$ thick foil while the south sensor is uncovered. Several hundred particles have been detected by the Helios 1 space probe. The fluxes of particles between 1 and $0.5 \mathrm{~A} . \mathrm{U}$. steadily increase with decreasing distance to the sun, although between 0.5 and $0.3 \mathrm{~A} . \mathrm{U}$. this increase is less steep. (Grün et $\alpha$ l, 27.106.016; Pailer and Grün, 27.022.118).

Concerning the dynamics, the comparison of recordings between the two sensors makes it possible to distinguish between two different types of orbits and particles. Low density particles $\left(<1 \mathrm{~g} / \mathrm{cm}^{3}\right)$ are orbiting the sun on elliptic orbits (eccentricities $>0.4$ ) while normal density particles remain on quasicircular orbits (eccentricities <0.4) around the sun. The properties and the orbits of the first class of particles indicates a cometary origin, and one might assume that the second class of particles is of asteroidal origin. However, the Pioneer 10/11 dust experiments did not measure any dust enhancements within the asteroidal belt, and therefore it seems more likely that the "young" cometary particles on elliptical orbits slowly change their structures and become more dense due to thermal influences during perihelion passages. Particles with densities $>1 \mathrm{~g} / \mathrm{cm}^{3}$ on quasi-circular orbits are in this sense "old".

The meteoroid penetration detectors on Pioneer 10 and 11 consist of pressurized cells covered with stainless steel (25 $\mu \mathrm{m}$ thickness on Pioneer 10 and $50 \mu \mathrm{m}$ on Pioneer 11). A meteoroid penetrating a cell causes a loss of pressure and is thereby recorded. The respective threshold sensitivities are approximately $10^{-9} \mathrm{~g}$ for Pioneer 10 and $10^{-8} \mathrm{~g}$ for Pioneer 11 . Earlier publications reported a constant spatial number density of dust particles between 1 and $5 \mathrm{~A} . \mathrm{U}$. even within the asteroidal belt with a substantial increase of the dust flux near Jupiter. In a recent publication Humes (28.106.079) reports that the spatial number density of meteoroids is constant even all the way out to 18 A.U. from the sun. Data obtained during the Saturn fly-by of Pioneer 11 shows that within 3.1 Saturnian radii the meteoroid flux increases by 3 orders of magnitude. From a comparison of particles recorded during three scans of the space between 4 and $5 \mathrm{~A}$.U. by Pioneer spacecraft with different attitudes it is concluded that the particles are in randomly inclined orbits of high eccentricity. This implies that the detected particles are on comet-like orbits and proves again 
that comets are the main sources of micro-meteoroids.

Some properties of interplanetary dust particles can be inferred from a study of lunar microcraters. These studies refer to the observation that diameter/depth ratios of lunar microcraters only depend on the projectile densities (Brownlee et al (12.094.524); Smith et al (12.094.145); Nage1 et al (14.094.181); Nagel and Fechtig (28.022.002). Lamy and Perrin (28.106.030) and Le Sergeant and Lamy (28.106.080, 22.106.058) have investigated the distribution of stony meteoroids versus iron meteoroids as a function of crater and projectile sizes. The general result is that the smaller the crater sizes the greater the proportion of iron meteoroids as compared to stony meteoroids.

From these observations the authors identify the sub-micron-sized $\beta-$ meteoroids with iron projectiles which leave the solar system on hyberbolic orbits. The inward spiralling meteoroids (diameter $>2 \mu \mathrm{m}$ ) are identified with stony meteoroids. A potential collisional or thermal production mechanism for $\beta-$ meteoroids close to the sun cannot be supported since the quantities of inspiralling mass and outgoing mass cannot be brought into any quantified agreement. From these two arguments it is concluded that the solar system dust cloud exhibits two fully independent populations: population 1 consists of large grains (diameter $>2 \mu \mathrm{m}$ ) with densities typical of silicates; population 2 consists of small grains (diameter $<2 \mu \mathrm{m}$ ) with densities typical of iron. This result, however, is still controversial as the authors have not considered the influence of the so-called $\alpha$-meteoroids which are produced within $0.5 \mathrm{~A} . \mathrm{U}$. of the sun by collisions, but are still large enough to remain on bound orbits until they collide again.

\section{INTERPLANETARY DUST - PHYSICAL CHARACTERISTICS AND SOURCES D.E. Brownlee.}

The sources of interplanetary dust are the interstellar medium and solar system bodies that do not have significant stable atmospheres. The major suppliers are comets and asteroids with comets widely believed to be the dominant source as they are the major producers of the millimeter meteoroids that produce visual meteors. A case has not been made that asteroid collisions are the major dust source but the present understanding of the dust complex is not compatible with known comets being the major source either. Kresak (28.106.032) has estimated that known comets replenish only $1 \%$ of the dust lost annually by collisions and Poynting Robertson drag. He suggests that the dust complex may be dominated by material released from rare, large comets. This would produce a dust complex that is only in quasi-equilibrium relative to processes which destroy dust. If this is the case then the spatial density and size distribution of dust should fluctuate significantly on time scales of $10^{4}-10^{5}$ years.

Sources of dust which are usually minor are ejecta from bodies of planetary size and interstellar grains which transit through the planetary system. Morfill and Grün (26.106.009) and Gustafson (26.131.100) discussed the Lorentz effect on small interstellar grains streaming through the solar system. Gustafson showed that if thermal velocities are small relative to streaming velocities, then magnetic focussing effects can produce large density enhancements in certain areas of the solar system and depletions in other regions. Morfill and Grü showed that except for favourable solar cycles, focussing and defocussing by the interplanetary magnetic field can prevent particles smaller than $10^{-5} \mathrm{~cm}$ (depending on the charge) from entering the inner regions of the solar system at low latitudes. Tomandl and Berg (21.106.025) measured an upper limit on the flux of interstellar grains at $1 \mathrm{~A}$.U. of $6 \times 10^{-5} \mathrm{~m}^{-2} \mathrm{~s}^{-1}$ for masses greater than $2 \times 10^{-14} \mathrm{~g}$. The measurement was made with the LEAM micro-meteorite detector placed on the Moon by Apol1o 17. Alexander (25.106.044) discussed processes by which submicron ejecta from lunar impacts could produce enhancement in the near earth dust flux at certain times in the lunar cycle. 
If the origin of interplanetary dust is material from comets which formed by accretion of pre-solar interstellar grains, then the dust should have properties compatible with aggregates of interstellar grains. Greenberg (28.106.045, $27.106 .010)$ suggests that the particles would be porous birdnest aggregates of core-mantle interstellar grains; the surviving mantle material would be carbonaceous materials altered by UV and charged particle irradiation in the interstellar medium.

New information on the physical properties of dust has been obtained from spacecraft measurements and laboratory analysis of recovered samples. Geise et al (21.106.031, 21.106.051, 28.106.021) conducted microwave analog experiments which suggest that the scattering functions and polarization of the zodiacal light are best reproduced by irregular porous and absorbing particles larger than $10 \mu \mathrm{m}$. Two particle populations for the zodiacal light was discussed by Lamy and Perrin (28.106.030). Evidence that the dust complex is composed of two components distinguished by size and composition was presented by LeSergeant and Lamy (22.106.058) and LeSergeant et $\alpha \mathcal{L}(28.106 .080)$. They indicate that lunar microcrater data on size distribution and crater morphology is consistent with particles $>2 \mu \mathrm{m}$ being silicates and particles $<2 \mu \mathrm{m}$ being metallic iron. This is not compatible with collected sample results but it is a hypothesis that can be tested by future spacecraft experiments. The spacecraft data from Helios presented by Grun et al (27.106.016) suggest a bimodal population but do not clearly indicate that there is a transition from pure iron to silicate at $2 \mu \mathrm{m}$. The Helios penetration data indicate that apex particles (fairly circular orbits) have moderate densities while $30 \%$ of the particles which have fairly elliptical orbits have densities of $<1 \mathrm{~g} \mathrm{~cm}^{-3}$.

Rather extensive laboratory studies have provided detailed information on the properties of mictometeorites recovered from the stratosphere. Hudson et $\alpha l$ (1980) measured rare gas contents of several particles proving that the particles are extraterrestrial and that they have probably been exposed to solar wind. The high measured Xe contents suggest that the particles may contain a large "planetary gas" component. Fraundorf et al (28.106.004) performed optical and IR transmission measurements on particles and detected the presence of the $\sim 1000 \mathrm{~cm}^{-1}$ silicate feature seen in the interstellar medium and in comet dust. Future studies will allow detailed comparison with astronomical sources and laboratory analogs. The isotopic composition of $\mathrm{Mg}$ was measured for several particles by Esat et at (26.106.019). The major result was that most particles had a normal isotopic composition at the $1 \%$ level althouth one particle was found with a $1.1 \%$ mass fractionation and most particles showed a hint of an excess of ${ }^{26} \mathrm{Mg}$ at a level of $\sim 0.4 \%$. Ganapathy et $a \mathrm{l}(26.106 .042)$ measured the trace element compositions of two $50 \mu \mathrm{m}$ particles using neutron activation and found them to agree with type I carbonaceous chondrites. Detailed electron microscope studies of particles were described by Fraundorf $(28.105 .129,1981)$, Flynn et al (25.105.173) and Brownlee et $\alpha$ l (28.106.044, 22.106.010, 22.106.001). The majority of collected particles are similar to carbonaceous chondrites but they differ in internal structure and mineralogy suggesting that they are a new kind of extra terrestrial material more porous and fragile than conventional meteorites. Atmospheric heating of micro-meteorites which could lead to thermal alteration was discussed by Fraundorf (28.106.071).

Deep sea spherules as a source of information on interplanetary dust was discussed by Brownlee (1981). Interpretation of deep sea spherules not as meteor ablation spherules but as rounded bodies created in space was described by Parkin (28.106.076, 22.106.047) and Hughes 28.106.052.

A literature review was made by Brownlee (26.106.047) and a popular review by Mi11man $(25.106 .072)$. 
References

Aikin, A.C.: 1981, Nature 291, p.638.

Arijs, E., Nevejans, D., and Ingels, J.: 1980, Nature 288, p.684.

Babadzhanov, P.B. and Zausaev, A.F.: 1980, Bu11. Astron. Inst. Akad. Nauk Tadjikistan, No. 69-70, p.54.

Babadzhanov, P.B., Zausaev, A.F. and Obrubov, Yu.: 1980, Bu11. Astron. Inst. Akad. Nauk Tadjikistan, No. 69-70, p.45.

Baggaley, W.J.: 1978, Nature 274, p.624.

Baggaley, W.J.: 1979a, Planet. Space Sci. 27, p.533.

Baggaley, W.J.: 1979b, Planet. Space Sci. 27, p.1131.

Baggaley, W.J.: 1980a, The Observatory 101, p.9.

Baggaley, W.J.: 1981a, Bull. Astron. Inst. Czech. 33, in press.

Baggaley, W.J.: $1981 \mathrm{~b}$, Nature 289 , p.530.

Baggaley, W.J. and Webb, T.H.: 1980, Planet. Space Sci. 28, p.997.

Baldwin, R.B.: 1981, Icarus 45, p.554.

Becher, H.J.: 1980, Sterne und We1traum, No. 6, p.222.

Bedard, A.J.Jr. and Green, G.E.: 1981, J. Acoust. Soc. 69, p.1277.

Bennett, J.C.: 1978, Monthly Notes Astron. Soc. S. Africa 37, p.85.

Bentor, Y. K.: 1979, Trans. Am. Geophys. Union 60, p.870.

Biberman, L.M., Bronin, S.Ya. and Brykin, M.V.: 1980, Acta Astronautica 7, p.53.

Bottomley, R. J.: 1979, Trans. Am. Geophys. Union 60, p.309.

Bouska,V.I., Povondra,P., Florenkij,P.V., Randa,Z.: 1981, Meteoritics 16, p.171.

Brownlee, D.E.: 1981, in The Sea, Vol. 7, ed. C. Emiliani, Wiley.

Ceplecha, Z.: 1967, Bul1. Astron. Inst. Czech. 18, p.233.

Ceplecha, Z.: 1981 SEAN Bul1. 6, No. 2, p.15.

Ceplecha, Z. and McCrosky, R.E.: 1976, J. Geophys. Res. 81, p.6257.

Ceplecha Z. Bocek, J., Novakova, M., Kirsten, I. and Kiko, J.: 1982, Bul1. Astron. Inst. Czech. 33, in press.

Chalmers, R.0., Henderson, E.P., Mason, B.: 1979, Bull. Geol. Soc. Am. 89, p.1455.

Cook, A.F. and Duxbury, T.C.: 1981, J. Geophys. Res., in press.

Crawford, A.R.: 1979, Geol. Mag. 116, p.261.

Dmitrievskij, A.A.: Astron. Vestn. 14, p.230.

Drummond, J.D.: 1981 , Icarus $48, \mathrm{p} .545$.

Dubin, M.: 1981, EOS (Trans. Amer. Geophys. Union), 62, p.321 (Abs).

Ferguson, E.E., Rowe, B.R. Fahey, D.W. and Fehsenfeld, F.C.: 1981, Planet. Space Sci. $29, \mathrm{p} .479$

Fraundorf, P.: 1981, Geochim. Cosmochim. Acta 45, p.915.

Gadsden, M.: 1978, J. Geophys. Res. 83, p.1155.

Glass, B.P.: 1979, Geology 7, 351.

Hajduk, A. and Cevolani, G.: 1981, Bu11. Astron. Inst. Czech., in press.

Hajdukova, M., and Hajduk, A.: 1981, Astron. et Geophys. 6, p.15.

Halliday, I., Griffin, A.A. and Blackwe11, A.T.: 1981 Meteoritics 16, p.153.

Halliday, I. and Griffin, A.A.: 1981, Meteoritics 16, in press.

Haskin, L.: 1980, Lunar Planet. Sci. Conf. XI, p.410.

Herrmann, U., Eberhardt, P., Hidalgo, M.A., Kopp, E. and Smith, L.G.: 1978, Space Res. 18, p. 249.

Hudson, B., Flynn, G.J., Fraundorf, P., Hohenberg, C.M. and Shirek, J.: 1980, Science $211, \mathrm{p} .383$.

Hughes, D.W., Williams, I.P. and Fox, K.: 1981, MNRAS, 195, p.625.

Hunten, D.M., Turco, R.P. and Toon, O.B.: 1980, J. Atmos. Sci. 37, p.1342.

Jones, J. and Morton, J.D.: 1981, Monthly Notices Roy. Astron. Soc., in press.

Jones, W.B., Bacon, M. and Hastings, D.A.: 1981, Bu11. Geo1. Soc. Am. 92, p.342.

Kalchenko, B.V. and Kashcheyev, B.L.: 1981, Meteor Researches 7, p.5.

Kazantzev, A.M. and Sherbaum, L.M.: 1981, Prob1. kosm. phys. 16, p.30.

Kerker, M.: 1981, Planet. Space Sci. 29, p.127.

King, E. A.: 1979, Geology 7, p.328.

Kovshun, I.N. and Smirnov, V.A.: 1978, Astron. Vestn. 12, p.199.

Kramer, E.N., Markina, A.K. and Shestaka, I.S.: 1980, Astron. Vestn. 14, p.202. 
Kramer, E.N., Musiji, V.I. and Shestaka, I.S.: 1980, Akad. Nauk Tadjikistan SSR, Komety $i$ Meteory, No. 29-31, p.83.

Kramer, E.N. and Shestaka, I.S.: 1977, Astron. Vestn. 11, p.i2.6.

Kramer, E.N. and Shestaka, I.S.: 1981, Comet Circ. USSR 274, p.4.

Kramer, E.N. and Timczenko, E.A.: 1981, Astron. Vestn. 15, p.50.

Lebedinets, V.N.: 1981, Astron. Vestn. 15, p.36.

Levitsky, S.M. and Abdrakhmanov, N.: 1978, Geomag. Aeronomy 18, p.497.

Liu, S.C. and Reid, G.C.: 1979, Geophys. Res. Lett. 6, p.283.

Mason, B.: 1979, Smith. Contr. Earth Sciences, No. 22, p.14.

McIntosh, B.A. and Hajduka, A.: 1977, Bull. Astron. Inst. Czech. 28, p.280.

McLeod, N.W.: 1981, Sky and Telescope 61, p.502.

Megie, G. and Blamont, J.E.: 1977, Planet Space Sci. 25, p.1093.

Murad, E. and Swider, W.: 1979, Geophys. Res. Lett. 6, p.929.

Nevski1, A.P.: 1979, So1. Sys. Res. 12, p.173.

Novakova, H.: 1979, Sterne und Weltraum, No. 11, p.382.

Novakova, H.: 1981, Sterne und Weltraum, No. 6-7 p.254.

Novikov, G.G., Tzigankov, S.F. and Blokhin, A.V.: 1981, Geomag. Aeron. 21, p.105.

0 'Keefe, J.A.: 1980, Nature 285, p.301.

Pecina, P. and Ceplecha, Z.: 1982, Bul1. Astron. Inst. Czech. 33, in press.

Perry, R.A., Rowe, B.R., Viggiano, A.A., Albritton, D.L., Ferguson, E.E. and Fehsenfe1d, F.C.: 1980, Geophys. Res. Lett. 7, p.693.

Petrov, G.I. and Stulov, V.P.: 1975, Cosmic Res. 13, p.525.

Polnitzky, G.: 1981 SEAN Bu11. 6, No. 5, p.15.

Poole, L.M.G.: 1978, Nature 274, p.624.

Poulter, E.M.: 1980, J. Atmos. Terr. Phys. 42, p.69.

ReVe1le, D.0.: 1981a, 1981b, J. Geophys. Res., in press.

Richter, E.S. and Sechrist, C.F.: 1979, Geophys. Res. Lett. 6, p.183.

Richter, E.S. Rowlett, J.R., Gardner, C.S. and Sechrist, C.F.: 1981, J. Atmos. Terr. Phys. 43, p.327.

Russe11, J.A.: 1980, Meteoritics 15, p.361.

Saldov,K.Kh. and Zolova,O.F.: 1980, Bull. Astrophys. Inst., Dushanbe 69-70, p.71.

Sepri, P., Chen, K.K. and O'Keefe, J.A.: 1981, J. Geophys. Res. 86, p.5103.

Shaw, H.F. and Wasserburg, G.J.: I981, Lunar Planet. Sc1. Conf. XII.

Sherbaum, L.M. and Kazantzev, A.M.: 1980, Vestn. Kiev. Univ. 22, p.61.

Shukla, P.N, and Goel, P.S.: 1979, Geochim. Cosmochim. Acta 43, p.1865.

Simek, M. and Hajduk, A.: 1981, Bull. Astron. Inst. Czech. 32, p.120.

Simonenko, A.N., Kruchinenko, V.G. and Sherbaum, L.M.: 1980, Meteoritika 39, p.121.

Storzer, D, and Wagner, G.A.: 1980, Naturwiss. 67, p.90.

Tkachuk, A.A.: 1978, Meteor Researches 5, p.67.

Tkachuk, A.A.: 1981, Meteor Researches 7, p. 28.

Tkachuk, A.A. and Matsenko, S.V.: 1981, Meteor Researches 7, p.63.

Turco, R.P., Toon, O.B., Hami1, P. and Whitten, R.C.: 1981, JGR, 86, p.1113.

Van Patter,D.M., Swann,C.P. and Glass, B.P.:1981, Geochim Cosmochim Acta 45, p.229.

Voloschuk, Yu.I. and Kashcheyev, B.L.: 1981, Nauka, Moscow.

Voloschuk,Yu.I., Kashcheyev, B.L. and Tkachuck,A.A.:1981a, Astron. Vest. 15, p.125.

Voloschuk, Yu.I., Kashcheyev, B.L. and Tkachuck, A.A.: 1981b, Astron. Vestn. 15, No. 3 and No. 4 .

Webb, T.H.: 1981, Planet. Space Sci. 29, p.415.

Weeks, R.A., Nasrallah, M., Arafa, S. and Bishay, A.: 1980, J. Non-Crystalline Solids 38 and 39 , p.129.

Wetheri11, G.W. and ReVelle, D.0.: 1981, Icarus, in press.

Wood, J.: 1981, British Meteor Soc. 11, p.71.

Yabuki,H., Shima,M. and Yabuki, S.:1981; Sc1. Pps. Inst. Phys. Chem. Res. 75, p.41.

Znoj11, V., Simek, M., Grygar, J. and Hollan, J.: 1981, Bull. Astron. Inst. Czech. 32 , p.1.

W.G. ELFORD

President of the Commission 